\title{
Marine protected areas for spatially structured exploited stocks
}

\author{
G. N. Tuck ${ }^{1, *}$, H. P. Possingham ${ }^{2}$ \\ ${ }^{1}$ CSIRO Marine Research, GPO Box 1538, Hobart, 7001 Tasmania, Australia \\ ${ }^{2}$ Department of Applied and Molecular Ecology, The University of Adelaide, PB 1 Glen Osmond, South Australia 5064, Australia
}

\begin{abstract}
Many harvested marine and terrestrial populations have segments of their range protected in areas free from exploitation. Reasons for areas being protected from harvesting include conservation, tourism, research, protection of breeding grounds, stock recovery, harvest regulation, or habitat that is uneconomical to exploit. In this paper we consider the problem of optimally exploiting a single species local population that is connected by dispersing larvae to an unharvested local population. We define a spatially-explicit population dynamics model and apply dynamic optimization techniques to determine policies for harvesting the exploited patch. We then consider how reservation affects yield and spawning stock abundance when compared to policies that have not recognised the spatial structure of the metapopulation. Comparisons of harvest strategies between an exploited metapopulation with and without a harvest refuge are also made. Results show that in a 2 local population metapopulation with unidirectional larval transfer, the optimal exploitation of the harvested population should be conducted as if it were independent of the reserved population. Numerical examples suggest that relative source populations should be exploited if the objective is to maximise spawning stock abundance within a harvested metapopulation that includes a protected local population. However, this strategy can markedly reduce yield over a sink harvested reserve system and may require strict regulation for conservation goals to be realised. If exchange rates are high, results indicate that spawning stock abundance can be less in a reserve system than in a fully exploited metapopulation. In order to maximise economic gain in the reserve system, results indicate that relative sink populations should be harvested. Depending on transfer levels, loss in harvest through reservation can be minimal, and is likely to be compensated by the potential environmental and economic benefits of the reserve.
\end{abstract}

KEY WORDS: Marine protected areas - Optimal harvesting · Metapopulation dynamics

\section{INTRODUCTION}

Marine reserves, where exploitation is either banned completely or intensively controlled, are gaining increasing acceptance as a practical means to manage fisheries and conserve valuable marine resources (Ballantine 1987, Bohnsack 1993, Creswell \& Thomas 1997 , ANZECC 1998, Guénette et al. 1998). Scientific and social desires for species and ecosystem conservation have led to the preservation of a variety of ecologically significant habitats. While terrestrial habitats have received greater attention as far as preservation and

•E-mail: geoff.tuck@marine.csiro.au management are concerned, the benefits of preserving marine and estuarine habitats are only beginning to be realised (Fairweather \& McNeill 1993). Marine protected areas are currently receiving attention as a valuable fisheries management tool where further controls are required to prevent over-exploitation and to aid stock recovery (Quinn et al. 1993, Roberts 1997 , Allison et al. 1998).

As human impacts place an ever-increasing pressure on our living resources, marine reserves are playing a vital role in the comprehensive and adequate preservation of marine systems (Cresswell \& Thomas 1997). However, historically the main purpose of both marine and terrestrial reserves has been for their significant natural beauty, their high ende- 
mism and their role in harbouring threatened species. For example, Australia's Great Barrier Reef Marine Park, which occupies some $350000 \mathrm{~km}^{2}$, is a region of unparalleled beauty and diversity. However, this park accounts for nearly $90 \%$ of the total area of Australia's marine parks, leaving less than $1.5 \%$ of the Australian Fishing Zone outside of this area under marine reserve protection (Bridgewater \& Ivanovici 1993, McPhail 1997). Even within the Great Barrier Reef Marine Park there are substantial regions zoned for sustainable multiple use. This includes a manipulative experiment where fishing on selected reefs is controlled to explore the effects of line fishing (Reichelt 1997).

While marine reserves have clear conservation applications, they can also be applied as a fish stock and harvest regulatory mechanism (Bohnsack 1993, Dugan \& Davis 1993. Guénette et al. 1998). Prohibiting exploitation in known areas of high stock production, breeding grounds or nurseries can be used to boost abundance and possibly future catch (Russ et al. 1992, Lee Long \& Coles 1997, Roberts 1997). Refugia can be applied as an alternative to other regulatory measures, such as restricting season lengths, as a means of reducing fishing effort and maintaining stocks (Davis 1989. Armstrong et al. 1993, Quinn et al. 1993. Shepherd \& Brown 1993, Roberts 1997. Allison et al. 1998). Temporary marine reserves may also be employed in order to allow stock recovery from overfishing or damage from pollutants (Cook \& McGaw 1991, Tegner 1992)

There are many other situations in which a portion of an exploitable population is unharvested. Fishing may be financially undesirable in certain local populations due to these regions being prone to under-sized or unmarketable individuals (Shepherd \& Branden 1991). Sub-populations of harvested stock may reside in unsuitable habitat for fishing (e.g. depth, distance from port, untrawlable ground), as was the case for many populations before new technologies made these remote populations accessible (Davis 1989). Fishing activities may also be closed across jurisdictional boundaries, such as the commonwealth-managed Macquarie Island Patagonian toothfish trawl fishery where operations are excluded within the state controlled 3 nautical mile buffer zone surrounding the island (AFMA 1996).

Shepherd (1991) has suggested 3 main reasons why marinc roserves are a potentially valuable monugement tool: first, for research, as fishing can bias measurements of growth and make estimates of natural mortality difficult to obtain; second, harvest reserves can protect genetic diversity--due to fishers selecting faster growing individuals, over time selective harvesting may result in a reduction of growth rates, increases in fecundity at age, reductions in age at maturity and decreases in size at maturity (Brown \& Parman 1993. Policansky 1993); third, reserves could provide a restocking source for populations that experience dramatic declines in abundance over the exploited portion of their range (Tegner 1992).

When establishing a reserve system the objective may be nature conservation, profitability, or a combination of these goals. For example, there may be a predetermined site for the reserve, a region of high endemism, or an important refuge of a threatened species. In such cases, conservation is the main objective. The impact of reservation on a fishery may also be a concern. If a commercially valuable species inhabits the area proposed for preservation, then one may like to know the impact on economic again. Thus, the choice of habitat for preservation will depend upon the objectives of the sanctuary and multiple objectives may need to be considered. Regardless of the reason for the reserve choice, once a reserve is established, one still needs to determine optimal harvesting policies for the exploited local populations.

Many harvested populations exhibit distinct spatial structure (Frank 1992, Shepherd \& Brown 1993, Man et al. 1995, McDonald et al. 1997). Due to spatial heterogeneity, local populations are likely to experience differing environmental conditions which will then influence their local dynamics. These connected local populations together form a metapopulation (Levins 1969, Pulliam 1988, Hanksi \& Gilpin 1991). In a previous paper (Tuck \& Possingham 1994) we considered optimal harvesting policies for a fully harvested metapopulation, where all local populations are available for exploitation. This paper considers optimal harvesting strategies for a managed stock where one of two connected local populations is reserved. The principal questions we ask are: what is the optimal harvesting strategy? which stock should be reserved? and, what is the loss in harvest caused by reserve establishment?

Previous modelling of harvest closures. The effects of harvest refugia on fisheries had until recently received little attention in the fisheries modelling literature. While Beverton \& Holt (1957) are credited with the first model to consider harvest refugia as a fisheries management tool, refugia were scarcely considered again for another 3 decades. Beverton \& Holt (1957) used their yield per recruit model to consider the effect of th unfishable portion of a stock of ploite. They found that while yield may increase, the need for large reserves, accurate measurements of transfer rates, and the potential increased cost of finding fish could be prohibitive.

With increasing desires for marine biodiversity protection and the growing need to control the exploita. 
tion of our marine living resources, marine reserves have recently taken a much greater prominence in fisheries science. Extensions of the Beverton-Holt model (Beverton \& Holt 1957) have been used by Polacheck (1990) and DeMartini (1993) to explore the effects of harvest refugia on populations of harvested temperate zone fish and 3 types of tropical Pacific reef fish. Both authors found estimates of spawning stock biomass (SSB) and yield to depend upon refuge size, transfer rates between the refuge and the exploited habitat, and fishing mortality rate. They also found that marine sanctuaries could increase spawning stock biomass per recruit but that any increase in yield per recruit would generally be small.

Quinn et al. (1993) considered the effectiveness of harvest refugia for conservation and for harvest regulation. They applied their model to the red sea urchin Strongylocentrotus franciscanus which exhibits both pre-larval and post-larval Allee effects. The proportion of harvesting effort is varied in each patch, allowing the exploration of the effects of reserves (zero effort) or poaching (small effort). They found that harvest refugia are necessary for the population and the fishery to remain viable with certainty. They also suggested that harvest refugia may be especially useful where harvesting effort is difficult to control. Under these circumstances, sanctuaries provide a useful management alternative to limiting harvest efficiency.

Man et al. (1995) used a multiple patch presenceabsence metapopulation model to explore the effectiveness of marine reserves for conservation and exploitation. They found that reserves can mediate the effect of exploitation by providing a source of recruitment for over-exploited populations. Both yield and metapopulation abundance were maximised when half of all patches are occupied.

Guénette et al. (1998) provided a comprehensive summary of the models relating to marine reserves to date. Most studies that consider spatially structured populations and harvest refugia have used yield per recruit analyses and simulation modelling. In our paper an explicit model of both within and between patch dynamics is considered and equations are found that implicitly define the optimal harvesting strategy for the exploited stock. We consider the problem of optimally exploiting a local population that is connected by larval or juvenile transfer to an unharvested population. We explicitly define the spatial population dynamics using coupled difference equations and then search for analytic solutions using the method of Lagrange multipliers. We next consider how the optimal harvesting strategies affect yield and spawning stock abundances, and relate this to problems associated with reserve establishment and management.

\section{THE MODEI}

Assume that the fished population is composed of two well-mixed, spatially homogeneous local populations. Adults are assumed to be sedentary, and after a period of local spawning, larvae produced by the adults of the local populations either recruit back to the parental population, move to the other local population or are lost from the system (see Fig. 1). A model of this form may be most applicable to benthic marine invertebrates or reef fish with pelagic larvae (Carr \& Reed 1992, Shepherd \& Brown 1993, Roberts 1997). Assume that the metapopulation is exploited by a single owner or authority. Managers are able to uniquely define the local populations and regulation measures can be applied to the individual sites.

We begin by describing the metapopulation using coupled difference equations (Tuck \& Possingham 1994, Supriatna \& Possingham 1998). The state space is composed of the abundances of these local populations. Following Clark (1976), we establish an economic framework and use the method of Lagrange multipliers to find optimal policies for the maximisation of discounted net revenues from the exploited population.

Let the dynamics of the unexploited metapopulation be modelled with the following difference equations:

$$
\begin{aligned}
& R_{1 k+1}=\delta_{1} R_{1 k}+p_{11} G_{1}\left(R_{1 k}\right)+p_{21} G_{2}\left(R_{2 k}\right) \\
& R_{2 k+1}=\delta_{2} R_{2 k}+p_{12} G_{1}\left(R_{1 k}\right)+p_{22} G_{2}\left(R_{2 k}\right)
\end{aligned}
$$

where $R_{j k+1}$ is the number of adults in local population $i$ at the beginning of the $k+1$ th period. The proportion of adults surviving per generation in the ith local population is represented by $\delta_{i}$ and $p_{i j}$ is the proportion of the larvae produced by local population $i$

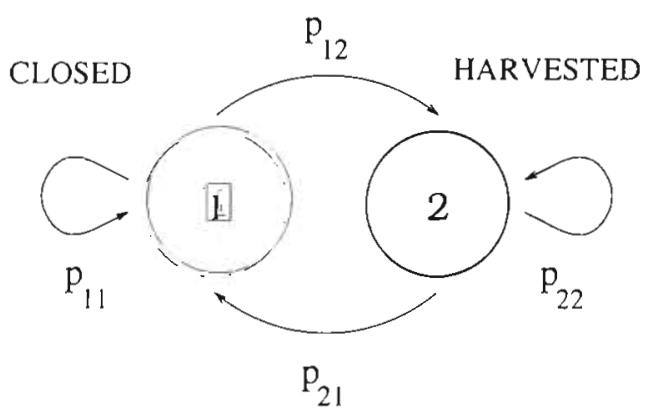

Fig. 1. A metapopulation with 2 local populations. The shaded local population is the unharvested reserve. The parameters $p_{1 y}$ represent the proportion of the larval production from local population $i$ that transfers to local population $j$ in each generation 
that recruit to local population $j$ in each generation. Assume that the remaining larvae of local population $i, \epsilon_{i}$, are lost from the system, so $p_{i 1}+p_{i 2}+\epsilon_{i}=1$ (Carr $\&$ Reed 1992). The function $G_{1}\left(R_{i k}\right)$ is the larval production function for local population i. For example, we might assume a logistic form for the production function, namely

$$
G_{i}\left(R_{i k}\right)=r_{l} R_{1 k}\left(1-R_{i k} / K_{l}\right)
$$

where $r$, is a growth rate and $K_{1}$ is a form of carrying capacity that causes density dependence in the per capita growth rate of local population $i$.

Assume that one of the local populations is to be reserved or closed. Without loss of generality assume that local population 1 is closed and local population 2 is harvested. The escapement for local population 1 is the unharvested abundance, $S_{1 k}=R_{1 k}$. Local population 2 is harvested, $H_{2 k}$ and its escapement $S_{2 k}=R_{2 k}$ $H_{2 k}$ then grows according to Eqs. (1) \& (2). When harvesting is included, Eqs. (1) \& (2) become

$$
\begin{aligned}
& R_{1 k+1}=\delta_{1} R_{1 k}+p_{11} G_{1}\left(R_{1 k}\right)+p_{21} G_{2}\left(S_{2 k}\right) \\
& R_{2 k+1}=\delta_{2} S_{2 k}+p_{12} G_{1}\left(R_{1 k}\right)+p_{22} G_{2}\left(S_{2 k}\right)
\end{aligned}
$$

The objective is to maximise the present value of net revenues obtained from local population 2, namely maximise

$$
P V=\sum_{k=0}^{\infty} \alpha^{k} \Pi\left(R_{2 k}, H_{2 k}\right)
$$

subject to Eqs. (4) \& (5) and $0 \leq H_{2 k} \leq R_{2 k}$. The term $\alpha=1 /(1+d)$ is a discounting factor, where $d$ is the periodic discount rate or interest rate. The term $\Pi\left(R_{2 k}, H_{2 k}\right)$ is the net revenue produced in period $k$ from a harvest of $\mathrm{H}_{2}$ from local population 2 and is:

$$
\Pi\left(R_{2 k}, H_{2 k}\right)=\int_{R_{2 k}-H_{2 k}}^{R_{2 k}}\left(p-C_{2}(x)\right) d x
$$

where $p$ is the price of the stock and $c_{2}(x)$ is the cost of harvesting a unit of stock from local population 2 when its abundance is $x$ (Clark 1990).

The method of Lagrange multipliers is used to find an equation which implicitly defines the optimal harvesting strategy for the exploited patch (see Clark 1976, 1990). The details of the derivation are given in the appendix. The equilibrium escapement that maximises Eq. (6) is $S_{2}$, which is implicitly defined by the cquality

$\frac{1}{\alpha}=\frac{\left(\Pi_{R_{2}}+\Pi_{H_{2}}\right)}{\Pi_{H_{2}}}\left[\delta_{2}+p_{22} G_{2}\left(S_{2}^{*}\right)+\frac{\alpha p_{12} p_{21} G_{1}^{\prime}\left(R_{1}\right) G_{2}^{\prime}\left(S_{2}^{*}\right)}{1-\alpha\left(\delta_{1}+p_{11} G_{1}^{\prime}\left(R_{1}\right)\right.}\right](8)$

where

$\Pi_{R_{2}}=\left[p-c_{2}\left(R_{2}\right)\right]-\left[p-c_{2}\left(S_{2}^{*}\right)\right]$ and $\Pi_{H_{2}}=\left[p-c_{2}\left(S_{2}^{*}\right)\right]$
If $G_{i}\left(S_{1}\right)$ is defined by Eq. (3) then $G^{\prime}{ }_{i}\left(S_{i}\right)=r_{i}\left(1-2 S_{1} / K_{i}\right)$. The equilibrium abundances are:

$$
\begin{aligned}
& R_{1}=\delta_{1} R_{1}+p_{11} G_{1}\left(R_{1}\right)+p_{21} G_{2}\left(S_{2}^{*}\right) \\
& R_{2}=\delta_{2} S_{2}^{*}+p_{12} G_{1}\left(R_{1}\right)+p_{22} G_{2}\left(S_{i}^{*}\right)
\end{aligned}
$$

Note that we are assuming that the mechanism of harvesting control is sufficiently flexible to hold the populations at equilibria that would be unstable if the harvest instead of the escapement were fixed (Roughgarden \& Smith 1996).

\section{INTERPRETATION OF THE RESULT}

It is difficult to interpret our main result, Eq. (8), directly since it is an implicit expression for the optimal escapement for the harvested population $S_{2}$, and so we discuss some special cases with reference to 2 types of local population and then consider some numerical examples.

\section{Local population classifications}

Following Tuck \& Possingham (1994), we make 2 biological classifications of local populations according to their per capita recruit production, i.e. the number of recruits produced per individual in a local population when the abundance is small.

\section{Relative exporters/importers}

First, consider a local population, local population i, that exports a greater per capita number of larvae to another local population, local population $j$, than local population $j$ exports to it. We call such a local population a 'relative exporter' local population. Mathematically, local population $i$ is a 'relative exporter' (relative to local population $j$ ) if

$$
r_{1} p_{l}>r_{j} p_{\mu}
$$

Similarly, a local population that imports a greater per capita number of larvae than it exports we call a 'relative importer' local population and it is defined by reversing the above inequality.

\section{Relative sources/sinks}

Consider a local population whose per capita recruit production is greater than the other local population's per capita recruit production. We call this local popula- 
tion a 'relative source' local population. Population $i$ is a 'relative source' local population (relative to local population $j$ ) if

$$
r_{i}\left(1-\epsilon_{i}\right)>r_{j}\left(1-\epsilon_{j}\right)
$$

A 'relative sink' is the local population that has the smaller per capita recruit production.

\section{Unidirectional transfer}

If there is no transfer between the local populations in one direction or in both directions, i.e. $p_{12}=0$ and/or $p_{21}=0$, then the implicit equation for the optimal harvesting strategy, Eq. (8), reduces to

$$
\frac{1}{\alpha}=\left(\frac{p-c_{2}\left(R_{2}\right)}{p-c_{2}\left(S_{2}\right)}\right)\left[\delta_{2}+p_{22} G_{2}^{\prime}\left(S_{2}\right)\right]
$$

This equation gives an optimal escapement $S_{2}^{*}$ that is the same as that obtained if local population 2 were not connected by larval transfer to the reserve in local population 1 (Clark 1990).

To explain this, first consider the case where there is no larval exchange from the reserve to the exploited population, $p_{12}=0$. If $p_{12}=0$ then the harvested local population's abundance is independent of the reserved local population and it is harvested as a single population with population dynamics given by

$$
R_{2 k+1}=\delta_{2} S_{2 k}+p_{22} G_{2}\left(S_{2 k}\right)
$$

As expected, Eq. (13) defines the optimal escapement for a population with the above growth characteristics. The harvested local population sends larvae to the closed local population; however, this does not affect the optimal harvesting decision for local population 2 .

If there is no larval exchange from the harvested population to the reserve, $p_{21}=0$, the explanation is not intuitively obvious. If costs are assumed negligible, and larval production is logistic, then from Eq. (13) the optimal escapement for the exploited local population is

$$
S_{2}=\frac{K_{2}}{2}-\frac{K_{2}}{2}\left[\frac{1+d-\delta_{2}}{r_{2} p_{22}}\right]
$$

This suggests that the optimal escapement of local population 2 is not influenced by the input of larvae from the reserve. Because the abundance of the reserve population is independent of the harvested stock, any larvae that transfer to the exploited local population are 'bonuses' to the harvest, and do not influence the equilibrium harvesting decision. If we think of $S_{2}^{\cdot}$ as the level to which the stock should be reduced to maximise growth, then this harvest strategy is not affected by the arrival of more individuals. While the escapement is the same as if there were no reserve, the harvest can be greater.

\section{Comparisons with incorrect harvesting policies}

As our theory generates optimal harvesting policies, one question we will want to answer is how the policies differ from those predicted by existing single population theory. Two possible incorrect harvesting policies that could be employed if the metapopulation structure has not been recognised include (1) that the local populations have been recognised but they are believed to be reproductively isolated, i.e. recruitment is assumed to be local and there is no exchange between the 2 stocks, and (2) that the metapopulation is incorrectly assumed to be a well-mixed single population, i.e. a population with reproductive interactions equally likely across the whole population.

We would then like to know under what circumstances the exploited local population's optimal escapement is larger or smaller than the escapement used if the metapopulation is mismanaged. As described in the previous section, analytic results are not facilitated by the nonlinear form of Eq. (8), and so we only consider the special case of unidirectional transfer and negligible or density-independent costs. However, a more general numerical example is given later in the paper.

Assume that $p_{21}=0$ and/or $p_{12}=0$. With no costs, Eq. (8) simplifies to

$$
\frac{1}{\alpha}=\delta_{2}+p_{22} G_{2}^{\prime}\left(S_{2}^{*}\right)
$$

and with logistic larval production the optimal escapement for local population 2 is equivalent to Eq. (15).

Assume that the authority managing the metapopulation has recognised the 2 local populations but does not believe there is any larval exchange between them. One of the local populations is reserved, local population 1, and the other local population is harvested. The growth rate for local population 2 is estimated as the 'flow in' to the local population

$$
r_{2 s}=r_{2} p_{22}+r_{1} p_{12}
$$

This estimate assumes that the growth rate is measured from the sedentary larvae of local population 2 and, unwittingly, the immigrants from local population 1. It also assumes that the population sizes are roughly equal, and that measurements are made after dispersal. 
There are 2 possibilities for unidirectional flow. First, assume that there is no larval transfer from the exploited population to the reserve, i.e. $p_{21}=0$. In this case, the optimal escapement of local population 2 from our metapopulation theory (Eq. 15) is greater than that if the local populations are assumed unconnected, $S_{2}^{*}>S_{2 s,}^{*}$ if $r_{1} p_{12}<0$. This inequality is not feasible, suggesting that managers may overestimate the optimal escapement of the exploited local population if the spatial structure of the metapopulation has not been recognised. The second case of unidirectional flow occurs when larval exchange only occurs from the exploited population to the reserve, and so $p_{12}=0$. We find that the escapements from both the correct metapopulation harvesting strategy and the incorrect policy are exactly the same, i.e. Eq. (15). As described in the previous section, in these special circumstances, the optimal escapement is not influenced by larval transfer in and out of local population 2 , and given that $p_{12}=0$, the incorrect harvesting policy will estimate the correct growth rate for local population 2 and the same optimal escapement.

The metapopulation could also be managed as one well-mixed single population. Establishing a reserve system then requires half of the population to be set aside for preservation, the other half for exploitation (assuming $K_{1}=K_{2}$ ). The estimated growth rate of the exploited half of the population is assumed to be the average per capita recruit production

$$
r_{L}=\frac{r_{1}\left(p_{11}+p_{12}\right)+r_{2}\left(p_{22}+p_{21}\right)}{2}
$$

Assume that there is no larval flow from the exploited local population to the reserved local population, i.e. $p_{21}=0$. The escapement from our metapopulation theory is greater than the estimated escapement if the local population is assumed to be part of a well-mixed single population, $S_{i}>S_{i} / 2$, if $I_{2} p_{22}>$ $r_{1}\left(p_{11}+p_{12}\right)$. This result is similar to the rule of thumb from Tuck \& Possingham (1994); namely, if the per capita recruit production in local population 2 is greater than that of local population 1, then the escapement of local population 2 should be larger than the escapement of local population 1 Thus, if the exploited population is a relative source, then management that assumes that the metapopulation is a single population may over-harvest the population.

Now assume that the unidirectional flow is from the expluited local population to the reserve, and there is no larval flow from the reserve, i.e. $p_{12}=0$. In this case the optinal escapement if the metapopulation structure is recognised is greater than that if it is not, $S_{i}>S_{L}^{*} / 2$, if $r_{2} p_{22}>r_{1} p_{11}+r_{2} p_{21}$. Thus, the exploited local population will have a lower escapement level than is optimal and may be over-harvested if more larvae per capita remain within the harvested local population than flow into the reserve.

A precautionary approach to management may suggest that it is better to err on the side of unconnected single population management, where either the harvest policy is correct or under-harvests the stock, than a management policy that assumes that the metapopulation is a well-mixed single population. These results apply to the special case of unidirectional transfer. The following section considers some more general cases through numerical examples.

\section{NUMERICAL RESULTS}

In this section we consider some general examples that help explore our main result in more detail. The following examples compare harvesting strategies for a metapopulation that is partially closed with that of harvesting both local populations. Comparisons are also made with harvesting strategies that have not recognised the spatial structure of the metapopulation.

\section{Optimal harvesting of a metapopulation}

Consider a metapopulation with the following parameters: $\delta_{1}=\delta_{2}=0.65$, a logistic larval production function with $r_{1}=r_{2}=5, K_{1}=K_{2}=2000$ and larval transfer matrix

$$
P=\left(\begin{array}{cc}
0.1 & 0.14 \\
0.06 & 0.1
\end{array}\right)
$$

where the $(i, j)$ th entry is the proportion of larvae transferring from local population $i$ to local population $j$. Local population 1 is a relative source/exporter population, and local population 2 is a relative sink/importer population. While this is a fictitious example, the parameters have been chosen to represent what may be a population of abalone (Shepherd 1990, Shepherd \& Breen 1992, Shepherd \& Brown 1993) or reef fish (Carr \& Reed 1992, Roberts 1997). The cost function is

$$
c(x)=\frac{a}{q x}
$$

where $a=30$ and $q=0.013$. The price of a unit of fished stock is $p=70$.

The unharvested equilibrium population sizes are

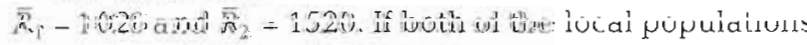
are harvested then according to Tuck \& Possingham (1994) the optimal escapements are $S_{i}^{*}=633$ and $S_{i}^{*}=477$, with equilibrium harvests $H_{i}=103$ and $H_{2}^{*}=317$. We might now like to know how these escapements and harvests differ if one of the local populations is reserved. 
If local population 1 is reserved then the escapement for local population 2, the harvested local population, is $S_{2}^{*}=296$ with harvest $H_{2}^{*}=371$. The equilibrium abundance in local population 1 is $R_{1}=928$. If local population 2 is reserved then the escapement for local population $1_{\text {, is }} S_{i}^{*}=210$ with harvest $H_{i}^{*}=169$. The equilibrium abundance in local population 2 , is $R_{2}=$ 1086. As expected, this shows that reserving local population 1, the relative source/exporter, produces the greatest harvest for the exploited patch. Note that a lower escapement in the exploited population does not necessarily lead to a greater harvest, as shown by the lower harvest and smaller optimal escapement when local population 1 is exploited. The results are summarised in Table 1.

The total harvest from exploiting both local populations, $H_{T}=H_{1}+H_{2}=420$ is greater than the harvest when the relative sink/importer local population is harvested, $H_{2}^{*}=371$. This suggests that similar (but smaller) catches can be made in this reserve system to catches utilising both patches in the metapopulation if the stock is optimally harvested. An important measure of stock size is the spawning stock abundance (SSA). The spawning stock abundance is the number of adults that are left after harvesting and that contribute to the reproductive growth of the population in the next generation. If we have a fully harvested metapopulation, then the $\mathrm{SSA}$ is $S_{i}+S_{2}^{*}$. If one of the local populations is closed, then the SSA is $R+$ $S^{*}$. In this example, the spawning stock abundance is greater in the sink harvested reserve system $\left(S_{2}^{*}+R_{1}=1224\right)$ than in the fully harvested metapopulation $\left(S_{1}^{*}+S_{2}^{*}=1100\right)$. As far as management is concerned, the possible benefits of reservation (e.g. minimal environmental degradation, improved fishery regulation, tourism) may outweigh the economic cost of reserving the relative source local population.
If the relative sink is reserved, and the relative source exploited, there is a dramatic drop in the equilibrium harvest $\left(H_{i}^{*}=169\right)$, the economic consequences of which may be disastrous for fishers reliant on the resource. However, there is a further increase in spawning stock abundance over a fully harvested metapopulation. If economic benefits are associated with increased abundance (e.g. tourism), then reserving the relative sink may be worthwhile. For example, this situation may occur where coral reefs are important for both tourism and, to a lesser extent, harvesting (Ballantine 1987, Alcala 1988, Craik 1993).

The escapements and harvests can also be compared to those derived from incorrectly harvesting the metapopulation. Assume that the metapopulation is composed of two unconnected single populations. If the sink is harvested and the source reserved, the optimal escapement and SSA increase while the harvest decreases ( $H=341$ ) compared to a correctly managed sink harvested reserve $\left(H^{*}=371\right)$. The same trend holds for a source harvested population (see Table 1). If the metapopulation is managed as a well-mixed single population the SSA increases substantially and, as expected, harvests are not greater than if the metapopulation structure had been recognised.

\section{Reserve choice-source or sink?}

In this section we vary the transfer parameters, $p_{12}$ and $p_{21}$, so we can explore the effect of larval exchange on optimal harvesting policies and reserve choice. Consider a metapopulation with the same parameters as the previous example, but with the following transfer matrix

$$
P=\left(\begin{array}{ll}
0.1 & p_{12} \\
p_{21} & 0.1
\end{array}\right)
$$

Table 1. Comparison of escapements and harvests from different management policies. Results under the heading of True optima assume that the metapopulation structure has been recognised, whereas False optima results do not. The sink local population is local population 2. "Abundances immediately before harvesting. Spawning stock abundance (SSA) is the total number of adults from both populations that contribute to the abundance of the following generation

\begin{tabular}{|c|c|c|c|c|c|c|c|c|}
\hline & $S_{1}$ & $S_{2}$ & $R_{1}$ & $R_{2}$ & SSA & $H_{1}$ & $H_{2}$ & $H_{\text {Total }}$ \\
\hline \multicolumn{9}{|l|}{ True optima } \\
\hline Harvest both & 633 & 477 & $736^{\circ}$ & $794^{\circ}$ & 1110 & 103 & 317 & 420 \\
\hline Harvest sink & - & 296 & 928 & $667^{\circ}$ & 122.4 & - & 371 & 371 \\
\hline Harvest source & 210 & - & $379^{\circ}$ & 1086 & 1296 & 169 & - & 169 \\
\hline \multicolumn{9}{|l|}{ False optima } \\
\hline Harvest sink & - & 641 & 1082 & $982^{\circ}$ & 1723 & - & 341 & 341 \\
\hline Harvest source & 459 & - & $608^{\circ}$ & 1339 & 1798 & 149 & - & 149 \\
\hline \multicolumn{9}{|l|}{ Well-mixed } \\
\hline Harvest sink & - & 559 & 1056 & $914^{\circ}$ & 1615 & - & 355 & 355 \\
\hline Harvest source & 559 & - & $690^{\circ}$ & 1403 & 1962 & 131 & - & 131 \\
\hline
\end{tabular}


The transfer parameters range from 0.02 (most recruitment local) to 0.2 (most recruitment external), and all other parameters remain constant.

Fig 2 explores the effect of harvesting either the source or the sink local population in the metapopulation. In Fig 2 contour lines of the ratio of (a) the optimal escapement and (b) yield from the sink harvested system to that of the source harvested system are shown. Contours of this ratio are only given for the bottom right parameter space as the upper left area is a simple reflection of this region about the line $p_{12}=$ $p_{21}$ Without loss of generality, this assumes that local population 1 is the relative source/exporter population.

Fig $2 \mathrm{a}, \mathrm{b}$ indicates that if the relative sink/importer local population is exploited, then both the escapement and harvest are larger than if the relative source/exporter local population is exploited. If a manager's objective is to maximise the escapement of the exploited local population, then the relative source/exporter local population should be reserved. Harvesters also benefit if this strategy is employed through an increase in catch.

Fig. 2c shows the ratio of the equilibrium abundance of the unharvested local population in a sink harvested system to that in a source harvested system. If the objective is to maintain as large a population size as possible in the reserve, then the relative sink/importer local population should be preserved. However, the over-exploitation of a relative source/exporter local population could have a devastating effect on the preserved relative sink/importer local population, espe- cially if the sink is reliant on the influx of immigrants from the source for its existence. The possibility of stock collapse, which may be even more evident in a stochastically varying population, may sway the reserve decision in favour of the preservation of relative source/exporter local populations (Roughgarden \& Smith 1996, Roberts 1997, Guénette et al. 1998)

If the relative source/exporter local population is preserved, then even though abundance in the reserve is lower, the overall metapopulation size, $R_{T}=$ $R_{1}+R_{2}$, is in general greater than if the relative sink/importer local population. However, this measure of total population size includes the 'soon-to-beharvested' stock of the exploited local population. An alternative measure is the total spawning stock abundance, $R+S^{*}$ Fig. $2 d$ plots contours of the ratio of the spawning stock abundance in a sink harvested system to that in a source harvested system. From this figure we can see that the spawning stock abundance is greater when the relative source local population is harvested.

\section{Comparison with a fully harvested metapopulation}

Using the parameters of the previous example, we now consider how the spawning stock abundance and harvests differ if the metapopulation has a closed Iocal population or if it is fully harvested.

Fig. 3 shows the difference in spawning stock abundance of the 2 harvesting policies. Without loss of generality, we assume that local population 1 is closed and (a)

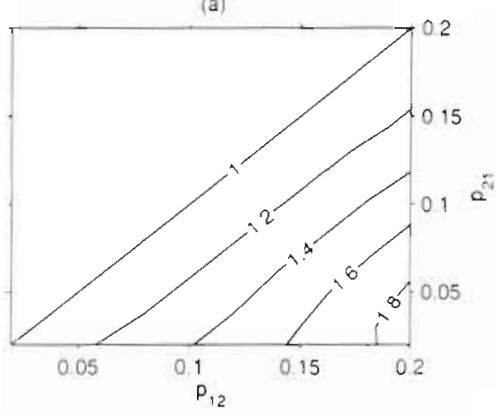

(c)

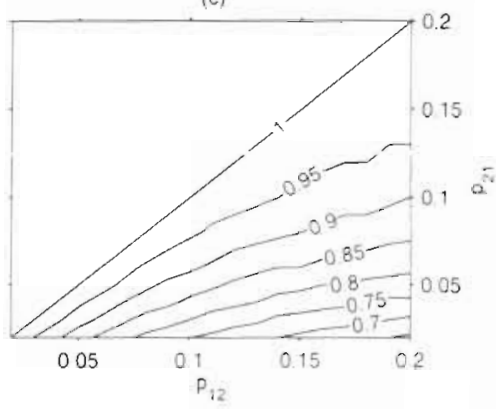

(b)

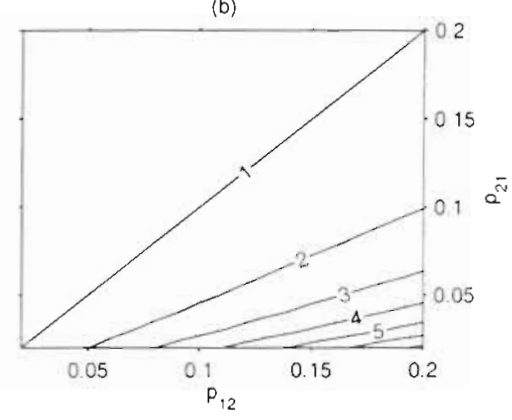

(d)

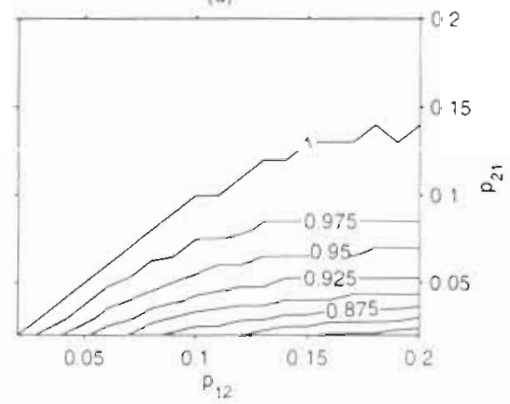

$a^{\overline{1}}$ Fig. 2. Ratio of (a) optimal escapement, (b) harvests, (c) abundance in the reserved population, and (d) total spawning stock abundance from a sink harvested metapopulation compared to a source harvested melapopulation. Local population 1 is the relative source and local population 2 is the relative sink 


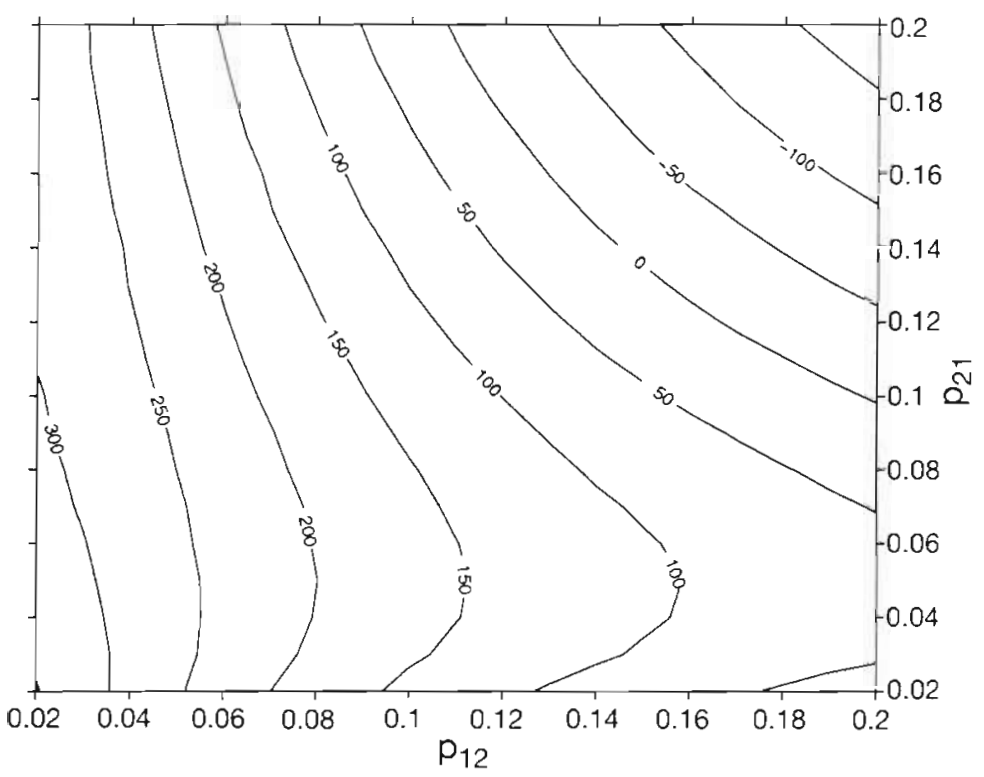

Fig. 3. Difference in spawning stock abundance (SSA) between a metapopulation with local population 1 closed and a fully harvested metapopulation. A positive number indicates that SSA is greater when local population 1 is reserved than if both local populations are harvested. The figure shows that if exchange rates are high, then SSA is less in a reserve system than in a fully exploited metapopulation

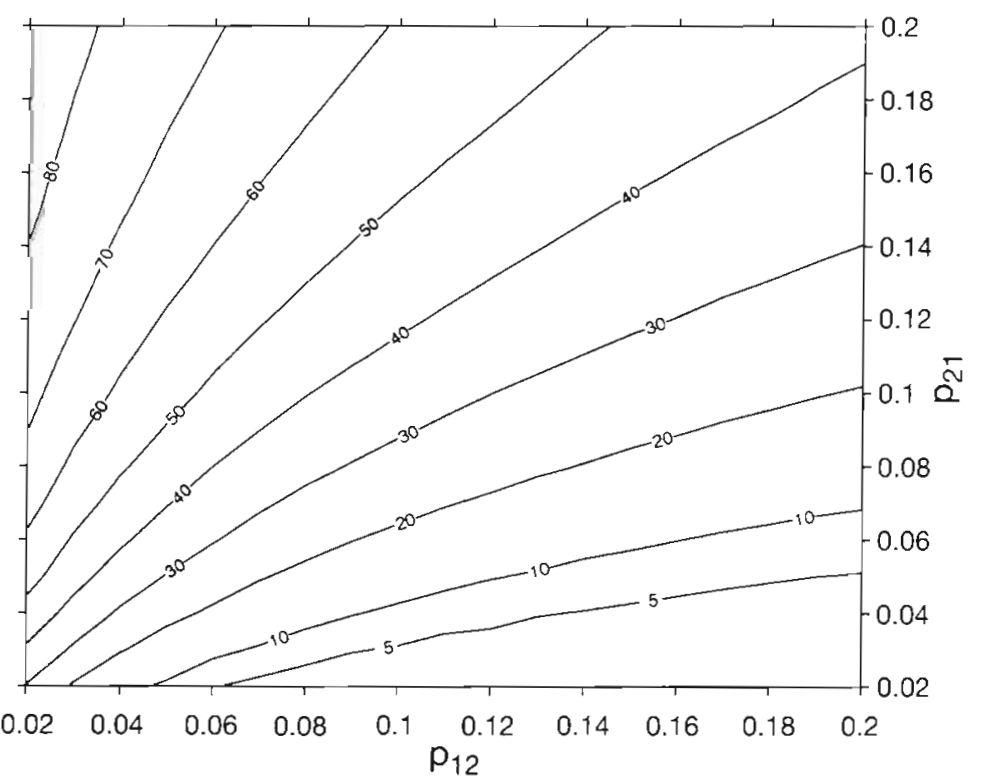

Fig. 4. Percentage loss in harvests between a fully harvested metapopulation and a metapopulation with local population 1 closed to exploitation. This difference is always non-negative, indicating that total harvests are always greater from a fully harvested metapopulation. The loss in yield is least when the sink local population is harvested and the source is reserved local population 2 is exploited. Thus the harvested local population is a relative sink/ importer if the point $\left(p_{12}, p_{21}\right)$ is below the line $p_{12}=p_{21}$, and it is a relative source/ exporter if above. Note that if $p_{12}$ and $p_{21}$ are large, then the SSA is larger in the fully harvested metapopulation than in the metapopulation with a local population reserved. Decreased benefits of reserves with high transfer rates have been found in other studies (Polacheck 1990, DeMartini 1993, Guénette \& Pitcher 1999). This has been explained to be a result of high transfer rates decreasing reproductive capacity through a decrease in mature stock in the reserve (Guénette et al. 1998). However, the model presented here does not include detailed age structure and yet still yields a similar conclusion. The large influx of recruits to the exploited population within the reserve system is able to sustain the exploited stock at a lower optimal escapement level than would be optimal in a fully exploited population.

The percentage loss in harvest by reserving one of the local populations in comparison to fully harvesting the metapopulation is shown in Fig. 4. This shows that, for our model, using closures as a management tool does not increase harvests. For all parameter values of this example, fully exploiting the metapopulation provides the greatest harvests. This result is intuitive, as removing a local population from harvesting decreases harvest potential. The degree of loss in harvest is least when the source local population is reserved and exchange from the source to the sink population is high. While most authors who have modelled harvest refugia find similar decreases in yield, some models that include a more explicit age structure show an increase in yield per recruit is possible under high levels of (nonoptimal) exploitation; the level of increase being dependent on the reserve size and transfer rates (Beverton \& Holt 1957, Polacheck 1990, Russ et al. 1992, DeMartini 1993, Quinn et al. 1993, Guénette et al. 1998).

\section{CONCLUSION}

In this paper we have considered the effects on optimal harvesting strategies of 
closing or reserving a local population within an exploited metapopulation. Harvest closures are currently receiving much attention because of their potential role in both conservation of biodiversity and fishery regulation.

Using coupled difference equations to model the harvested and closed local populations of a single-species 2-patch metapopulation, we derived an equation that implicitly defines the optimal equilibrium escapement for the harvested stock. This was achieved using the method of Lagrange multipliers.

For the special case of unidirectional transfer we have shown that the optimal escapement is independent of the transfer parameters, $p_{12}$ and $p_{21}$. If there is no larval transfer into the harvested local population then the harvested population's dynamics are not influenced by the reserved population, even though a proportion of the harvested population's larvae transfer into the reserve. When there is no larval transfer from the harvested population to the reserve, the abundance of the reserved population is independent of the exploited habitat, and additional larvae are then a 'bonus' to the controlled, harvested stock. This somewhat surprising result has important implications for the management of harvested reserve systems. If we can ascertain that there is unidirectional transfer in a 2-patch metapopulation, then the harvested population should be managed using the parameters of that patch, regardless of the larval transfer.

Comparisons with incorrect harvesting policies were then made with the assumption of unidirectional transfer. If the local populations are falsely believed to be unconnected by larval exchange, we find that the exploited local population is either under-harvested or correctly harvested, depending on the direction of larval flow. However, if the metapopulation is managed as a well-mixed single population, the exploited local population may be under- or over-harvested. Precautionary management might suggest that it is better to err on the side of unconnected single population management if unidirectional flow is suspected. In a numerical study with larval exchange between both local populations, we have shown that incorrect harvesting strategies (either with both local populations harvested or one reservedj do not yield more than the fully harvested metapopulation or the sink harvested reserve system. If the metapopulation structure is not recognised, and the relative source local population is exnloited, then haryests could be reduced dramatically.

Further results in the paper were obtained by varying the transfer parameters and holding all other parameters constant. These numerical examples suggested that maximum yield is obtained by exploiting the relative sink local population, rather than the relative source. This may be a sensible strategy to adopt, as harvesting source populations is fraught with the danger of a local collapse (Shepherd \& Brown 1993 Roberts 1997, Alison et al. 1998). However, to maximise the metapopulation's spawning stock abundance, our results suggest that relative source local populations should be harvested. A consequence of this policy, if export to import levels are high, is the possibility of a substantlal decrease in yield in comparison to a sink harvested reserve system. As previously mentioned, harvesting the source local population will require strict regulation for conservation goals to be realised.

The examples show that while yield is always less than that from a fully harvested metapopulation (assuming optimal policies are adopted), it is comparable for populations with high per capita transfer from the reserve local population to the harvested stock. Once again, this suggests that relative sink local populations should be harvested to maintain yield at a level that approximates that taken from a fully harvested metapopulation. The economic loss due to a decrease in harvests may be countered by the potential environmental and economic benefits of the reserve. A reserve system in which a relative source is harvested may increase spawning stock abundance but can reduce yield markedly. This strategy may be financially unwise, unless significant alternative gains can be made from other uses of the increase in abundance.

The model presented in this paper makes some basic assumptions about harvested stock dynamics. The main model assumptions include that the demographics of the population are known with certainty, that the economic framework can be based on maximisation of discounted net revenues and that a single managing authority is able to selectively harvest the local populations. While these assumptions may over-simplify realworld fisheries, the primary focus of the investigation has been on the transfer parameters, with all else equal, as this has allowed an exploration of the relationship between differential larval transfer, harvesting policies and reserve choice. In most fisheries, where biological and economic parameters are difficult to measure, the general rules of thumb described here may provide a useful guide for managers. The inclusion of additional factors, such as stochasticity, age-structure and a more complex economic model, may benefit future models of this kind, but could possibily cloud the relationships linking optimal harvesting strategies and the movement of recruits between lucal populations

Acknowledgements. The authors would like to thank David McDonald and Paul Armsworth for reviewing an earlier draft. of the paper. This paper is based on work presented in Chapter 5 of G.N.T's PhD thesis (Tuck 1994). 
Appendix. Derivation of the optimal harvesting equation for the exploited local population

We use the method of Lagrange multipliers to derive the optimal harvesting equation for the exploited local population. In finding interior solutions, we assign the Lagrangian

$$
\begin{aligned}
L=\sum_{k=0}^{\infty}\left\{\alpha^{k} \Pi\left(R_{2 k}, H_{2 k}\right)-\lambda_{1 k}\left[R_{1 k+1}-\delta_{1} R_{1 k}-p_{11} G_{1}\left(R_{1 k}\right)-p_{21} G_{2}\left(R_{2 k}-H H_{2 k}\right)\right]\right. \\
\left.\quad-\lambda_{2 k}\left[R_{2 k+1}-\delta_{2}\left(R_{2 k}-H_{2 k}\right)-p_{12} G_{1}\left(R_{1 k}\right)-p_{22} G_{2}\left(R_{2 k}-H_{2 k}\right)\right]\right\}
\end{aligned}
$$

with necessary conditions

$$
\begin{array}{ll}
\frac{\partial L}{\partial R_{i k}}=0 & k \geq 1, \quad i=1,2 \\
\frac{\partial L}{\partial H_{2 k}}=0 & k \geq 0
\end{array}
$$

Expanding Eq. (21)

$$
\begin{aligned}
& \frac{\partial L}{\partial R_{1 k}}=-\lambda_{1 k-1}+\lambda_{1 k}\left[\delta_{1}+p_{11} G_{1}^{\prime}\left(R_{1 k}\right)\right]+\lambda_{2 k} p_{12} G_{1}^{\prime}\left(R_{1 k}\right)=0 \\
& \frac{\partial L}{\partial R_{2 k}}=\alpha^{k} \Pi_{R 2}+\lambda_{1 k} p_{21} G_{2}^{\prime}\left(S_{2}^{*}\right)-\lambda_{2 k-1}+\lambda_{2 k}\left[\delta_{2}+p_{22} G_{2}^{\prime}\left(S_{2}^{*}\right)\right]=0
\end{aligned}
$$

and Eq. (22) becomes

$$
\frac{\partial L}{\partial H_{2 k}}=\alpha^{k} \Pi_{H_{2}}-\lambda_{1 k} p_{21} G_{2}^{\prime}\left(S_{2}^{*}\right)-\lambda_{2 k}\left[\delta_{2}+p_{22} G_{2}^{\prime}\left(S_{2}^{*}\right)\right]=0
$$

where $S_{2}^{*}$ is the optimal equilibrium escapement. Adding Eqs. (24) \& (25) we obtain

$$
\lambda_{2 k}=\alpha^{k+1}\left(\Pi_{R_{2}}-\Pi_{H_{2}}\right)
$$

Now, rewrite Eq. (25) as

$$
\lambda_{1 k}=\frac{\alpha^{k} \Pi_{H_{2}}-\alpha^{k+1}\left(\Pi_{R_{2}}+\Pi_{H_{2}}\right)\left[\delta_{2}+p_{22} G_{2}^{\prime}\left(S_{2}^{*}\right)\right]}{p_{21} G_{2}^{\prime}\left(S_{2}^{*}\right)}
$$

Substituting Eqs. (27) \& (26) into Eq. (23), we have

$$
\begin{aligned}
0=- & {\left[\frac{\alpha^{k-1} \Pi_{H_{2}}-\alpha^{k} \cdot\left(\Pi_{R_{2}}+\Pi_{H_{2}}\right)\left[\delta_{2}+p_{22} G_{2}^{\prime}\left(S_{2}^{*}\right)\right]}{p_{21} G_{2}^{\prime}\left(S_{2}^{*}\right)}\right] } \\
& +\left[\frac{\alpha^{k} \Pi_{H_{2}}-\alpha^{k+1}\left(\Pi_{R_{2}}+\Pi_{H_{2}}\right)\left[\delta_{2}+p_{22} G_{2}^{\prime}\left(S_{2}^{*}\right)\right]}{p_{21} G_{2}^{\prime}\left(S_{2}^{*}\right)}\right]\left[\delta_{1}+p_{11} G_{1}^{\prime}\left(R_{1}\right)\right] \\
& +\alpha^{k+1}\left(\Pi_{R_{2}}+\Pi_{H_{2}}\right) p_{12} G_{1}^{\prime}\left(R_{1}\right)
\end{aligned}
$$

where $R_{1}$ is the equilibrium abundance of local population 1

$$
R_{1}=\delta_{1} R_{1}+p_{11} G_{1}\left(R_{1}\right)+p_{21} G_{2}\left(S_{2}^{*}\right)
$$

Multiplying through by $p_{21} G_{2}^{\prime}\left(S_{2}^{*}\right)$ and dividing by $\alpha^{k+1}$ we produce

$$
\begin{aligned}
\frac{\Pi_{H_{2}}}{\alpha^{2}}-\frac{1}{\alpha}\left(\Pi_{R_{2}}+\Pi_{H_{2}}\right)\left[\delta_{2}+p_{22} G_{2}^{\prime}\left(S_{2}^{*}\right)\right] & =\left[\frac{\Pi_{H_{2}}}{\alpha}-\left(\Pi_{R_{2}}+\Pi_{H_{2}}\right)\left[\delta_{2}+p_{22} G_{2}^{\prime}\left(S_{2}^{*}\right)\right]\right]\left[\delta_{1}+p_{11} G_{1}^{\prime}\left(R_{1}\right)\right] \\
& +\left(\Pi_{R_{2}}+\Pi_{H_{2}}\right) p_{12} p_{21} G_{1}^{\prime}\left(R_{1}\right) G_{2}^{\prime}\left(S_{2}^{*}\right) p_{21} G_{1}^{\prime}\left(R_{1}\right) G_{2}^{\prime}\left(S_{2}^{*}\right)
\end{aligned}
$$

and so

$$
\begin{aligned}
0= & {\left[\frac{1}{\alpha}-\left[\delta_{1}+p_{11} G_{1}^{\prime}\left(R_{1}\right)\right]\right]\left[\left(\Pi_{R_{2}}+\Pi_{H_{2}}\right)\left[\delta_{2}+p_{22} G_{2}^{\prime}\left(S_{2}^{*}\right)\right]-\frac{\Pi_{H 2}}{\alpha}\right] } \\
& +\left(\Pi_{R_{2}}+\Pi_{H_{2}}\right) p_{12} p_{21} G_{1}^{\prime}\left(R_{1}\right) G_{2}^{\prime}\left(S_{2}^{*}\right)
\end{aligned}
$$

After algebraic rearrangement we find,

$$
\frac{1}{\alpha}=\frac{\left(\Pi_{R_{2}}+\Pi_{H_{2}}\right)}{\Pi_{H_{2}}}\left[\delta_{2}+p_{22} G_{2}^{\prime}\left(S_{2}^{*}\right)+\frac{\alpha p_{12} p_{21} G_{1}^{\prime}\left(R_{1}\right) G_{2}^{\prime}\left(S_{2}\right)}{1-\alpha\left[\delta_{1}+p_{11} G_{1}^{\prime}\left(R_{1}\right)\right]}\right]
$$

which implicitly defines the optimal escapement for the harvested patch, local population 2 . Note that $\Pi_{R_{2}}=\left[p-C_{2}\left(R_{2}\right)\right]-$ $\left[p-c_{2}\left(S_{2}^{*}\right)\right]$ and $\Pi_{H_{2}}=\left[p-c_{2}\left(S_{2}^{*}\right)\right]$ 


\section{LITERATURE CITED}

AFMA (1996) Macquarie Island Developmental Fishery Approved Management Policy November 8, 1996 Australian Fisheries Management Authority, Canberra

Alcala AC (1988) Effects of marine system reserves on coral fish abundances and yields of Philippine coral reefs. Ambio 12:194-199

Allison GW, Lubchenco J, Carr MH (1998) Marine reserves are necessary but not sufficient for marine conservation. Ecol Appl Supp 8:S79-S92

ANZECC (1998) Guidelines for establishing the national representative system of marine protected areas. December, 1998 Australian and New Zealand Environment and Conservation Council, Task Force on Marine Protected Areas. Environment Australia

Armstrong, DA, Wainwright TC, Jensen GC, Dinnel PA, Andersen HB (1993) Taking refuge from bycatch issues: red king crab (Paralithodes camtschaticus) and trawl fisheries in the eastern Bering Sea. Can J Fish Aquat Sci 50: 1993-2000

Ballentine B (1987) New Zealand's course for marine reserves New Sci 1563:54-55

Beverton RJHi Holt SJ (1957) On the dynamics of exploited fish populations. Fisheries Investigations Series 2(19). Ministry of Agriculture, Fisheries and Food, London

Bohnsack JA (1993) Marine reserves; they enhance fisheries, reduce conflicts and protect resources. Oceanus 36 : $63-71$

Bridgewater P. Ivanovici A (1993) Achieving a representative system of marine and estuarine protected areas for Australia. In: Ivanovici AM, Tarte D. Olson M (eds) Protection of marine and estuarine areas-a challenge for Australians: Proceedings of the fourth Fenner conference on the environment, Canberra, 9-11 October 1991 Australıan Committee for IUCN, Sydney, p 23-29

Brown JS, Parman AO (1993) Consequences of size selective harvesting as an evolutionary game. Lect Notes Biomath 99:248-261

Carr MH, Reed DC (1992) Conceptual issues relevant to marine harvest refuges: examples from temperate reef fishes. Can J Fish Aquat Sci 50:2019-2028

Clark CW (1976) A delayed-recruitment model of population dynamics, with an application to baleen whale populations. J Math Biol 3:281-391

Clark CW (1990) Mathematical bloeconomics: the optimal management of renewable resources, 2nd edn. WileyInterscience, New York

Cook BA, McGaw R (1991) Management of the New Brunswick commercial salmon lishery: an economic perspective. Mar Policy 15:33-38

Craik W (1993) The Great Barrier Reef Marine Park: A model for regional management. In: Ivanovici AM, Tarte $D$, Olson $M$ (eds) Protection of marine and estuarine areasa challenge for Australians: Proceedings of the fourth Fenner conference on the environment. Canberra 9-11 October 1991. Australian Committee for IUCN, Sydney, p 91-97

Creswell ID. Thomas GM (1997) Terrestrial and marine protected areas in Austraila. Environment Australıa, Canberra

Davis GE (1989) Designated harvest refugia: the next stage of marine fishery management in California. Calif Com Fish Ind Rep 30:53-58

DeMartini EE (1993) Modeling the potential of fishery reserves for managing Pacific coral reef fishes. Fish Bull $91: 414-427$
Dugan JE, Davis GE (1993) Applications of marine refugia to coastal fisheries management. Can J Fish Aquat Sci 50 $2029-2042$

Fairweather PG, McNeill S (1993) Ecological and other scientific imperatives for marine and estuarine conversation. In: Ivanovici AM, Tarte D, Olson M (eds) Protection of marine and estuarine areas - a challenge for Australians: proceedings of the fourth Fenner Conference on the environment, Canberra 9-11 October 1991 Australian Committee for IUCN, Sydney, p 39-48

Frank KT (1992) Demographic consequences of age-specific dispersal in marine fish populations. Can J Fish Aquat Sci 49:2222-2231

Guénette S, Pitcher TJ (1999) An age-structured model showing the benefits of marine reserves in controlling overexploitation. Fish Res in press 39:295-303

Guénette S, Lauck T, Clark C (1998) Marine reserves: from Beverton and Holt to the present. Rev Fish Biol Fish $8: 1-21$

Hanski I, Gilpin M (1991) Metapopulation dynamics: brief history and conceptual domain. Biol J Linn Soc 42:3-16

Lee Long WJ, Coles RG (1997) Impacts on and responses of seagrasses in the Great Barrier Reef-issues for management. In: The Great Barrier Reef, science, use and management a national conference: proceedings, Vol 1. Great Barrier Reef Marine Park Authority, Townsville, p $101-106$

Levins R (1969) Some demographic and genetic consequences of environmental heterogenelty for biological control. Bull Entomol Soc Am 15:237-240

Man A, Law R. Polunin NVC (1995) Role of marine reserves in recruitment to reef fisheries: a metapopulation model. Biol Conserv 71:197-204

McDonald AD, Smith ADM, Punt AE, Tuck GN, Davidson AJ (1997) Empirical evaluation of expected returns from research on stock structure for determination of total allowable catch. Nat Res Model 10:3-29

McPhail I (1997) Partnerships and collaboration: management of the Great Barrier Reef World Heritage Area, past, present and future. In: The Great Barner Reef, science, use and management a national conference: proceedings, Vol 1 Great Barner Reef Marine Park Authority, Townsitlle, p 5-8

Polacheck T (1990) Year around closed areas as a management tool. Nat Res Model 4:327-354

Policansky D (1993) Fishing as a cause of evolution in fishes. Lect Notes Biomath 99:2-18

Pulliam HR (1988) Sources, sinks and population regulation. Am Nat 132:652-661

Quinn JF, Wing SR, Botsford LW (1993) Harvest refugia in marine invertebrate fisheries: Models and applications to the red sea urchin, Strongylocentrotus franciscanus. Am Zool 33:537-550

Reichelt RE (1997) Advances in scientific research on the Great Barrier Reef since 1983. In: The Great Barrier Reef, science, use and management a national conference: proceedings, Vol 1. Great Barrier Reef Marine Park Authority, Townsville, p 9-19

Roberts CM (1997) Connectivity and management of Canbbean coral reets. Science 278:1454-1457

Roughgarden J. Smith F (1996) Why fisheries collapse and what to do about it. Proc Nat Acad Sci USA 93: 5078-5083

Russ GR, Alcala AC, Cabanban AS (1992) Marine reserves and fisheries management on coral reefs with preliminary modelling of the effects on yield per recruit. Proc 7 th int Coral Reef Symp 2:978-985

Shepherd SA (1990) Studies on southern Australian abalone 
(Genus Haliotis) XII. Long-term recruitment and mortality dynamics of an unfished population. Aust J Mar Freshw Res 41:475-492

Shepherd SA (1991) Marine reserves can be used to conserve abalone stocks. Safish 15(3):7-9

Shepherd SA, Branden KL (1991) Surveys of stunted abalone stocks continue in the south east. Safish 15(3):20

Shepherd SA, Breen PA (1992) Mortality in abalone: its estimation, variability and causes. In: Shepherd SA, Tegner MJ, Guzman del Proo SA (eds) Abalone of the world: biology, fisheries and culture. Blackwell Scientific Publications Inc, Cambridge, p 276-304

Shepherd SA, Brown LD (1993) What is an abalone stock:

Editorial responsibility: Kenneth Sherman (Contributing Editor), Narragansett, Rhode Island, USA implications for the role of refugia in conservation. Can J Fish Aquat Sci 50:2001-2007

Supriatnd AK, Possingham HP (1998) Optimal harvesting for a predator-prey metapopulation. Bull Math Biol 60:49-65

Tegner MJ (1992) Brood-stock transplants as an approach to abalone stock enhancement. In: Shepherd SA, Tegner MJ, Guzman del Proo SA (eds) Abalone of the world: biology, fisheries and culture. Blackwell Scientific Publications Inc, Cambridge, p 461-473

Tuck GN (1994) Optimal harvesting models for metapopulations. PhD thesis, The University of Adelaide

Tuck GN, Possingham HP (1994) Optimal harvesting strategies for a metapopulation. Bull Math Biol 56:107-127

Submitted: March 12, 1999; Accepted: July 30, 1999

Proofs received from author(s): January 21, 2000 